\title{
Evaluation of spheroid head and neck squamous cell carcinoma cell models in comparison to monolayer cultures
}

\author{
LORENZ KADLETZ ${ }^{1}$, GREGOR HEIDUSCHKA ${ }^{1}$, JULIAN DOMAYER ${ }^{1}$, RAINER SCHMID ${ }^{2}$, \\ ELISABETH ENZENHOFER ${ }^{1}$ and DIETMAR THURNHER ${ }^{1}$
}

\author{
Departments of ${ }^{1}$ Otorhinolaryngology, Head and Neck Surgery, and ${ }^{2}$ Radiotherapy, \\ Medical University of Vienna, Vienna A-1090, Austria
}

Received February 16, 2015; Accepted April 24, 2015

DOI: $10.3892 / 01.2015 .3487$

\begin{abstract}
Two-dimensional (2D) monolayer cell culture models are the most common method used to investigate tumor cells in vitro. In the few last decades, a multicellular spheroid model has gained attention due to its adjacency to tumors in vivo. The aim of the present study was to investigate immunohistochemical differences between these two cell culture systems. The FaDu, CAL27 and SCC25 head and neck squamous cell carcinoma (HNSCC) cell lines were seeded out in monolayer and multicellular spheroids. The FaDu and SCC25 cells were treated with increasing doses of cisplatin and irradiation. CAL27 cells were not used in theproliferation experiments, since the spheroids of CAL27 cells were not able to process the reagent in CCK- 8 assays. Furthermore, they were stained to present alterations of the following antigens: $\mathrm{Ki}-67$, vascular endothelial growth factor receptor, epithelial growth factor and survivin. Differences in growth rates and expression patterns were detected in certain HNSCC cell lines. The proliferation rates showed a significant divergence of cells grown in the three-dimensional model compared with cells grown in the 2D model. Overall, multicellular spheroids are a promising method to reproduce the immunohistochemical aspects and characteristics of tumor cells, and may show different response rates to therapeutic options.
\end{abstract}

\section{Introduction}

Malignant growth in the head and neck area affects a large group of individuals and remains a serious health issue; worldwide, $>600,000$ new cases of head and neck squamous cell carcinoma (HNSCC) are diagnosed every year (1). Within this group, cancer of the lips and the oral cavity are

Correspondence to: Mr. Gregor Heiduschka, Department of Otorhinolaryngology, Head and Neck Surgery, Medical University of Vienna, 18-20 Waehringer Guertel, Vienna A-1090, Austria E-mail: gregor.heiduschka@meduniwien.ac.at

Key words: head and neck squamous cell carcinoma, cell culture, multicellular spheroids, irradiation, cisplatin the most frequent, with an incidence of nearly 250,000 cases annually (1). The five-year relative survival rate varies from $20-90 \%$ depending upon the primary tumor site of the tumor and the clinical stage at the presentation of disease (2).

Treatment options for HNSCC include surgery and/or radio(chemo)therapy. Despite the plethora of novel chemotherapeutic agents, refined radiation protocols and carefully selected patients for surgery, the overall survival of affected patients has only improved marginally during the last 30 years (3). Nevertheless, the requirement for novel therapeutic approaches remains undisputed.

One common approach for the identification of potential therapeutic agents is tests in a monolayer cell culture system (4). In the last 50 years, a multitude of oncological studies have been performed with this classic two-dimensional (2D) model. Important advantages of this model are its wide availability, ease of use and low costs, and a number of significant discoveries have been gained from its application (5). However, the artificial environment limits cell-cell interactions and thus prohibits a number of the physiological processes present in solid tumors (6). Furthermore, studies indicate that 2D cell cultures are a poor predictor for clinical benefits $(7,8)$. These limitations are well-documented and the first attempts to mitigate these problems date back almost 40 years (9).

More sophisticated cell models were therefore developed. Multi-cellular spheroids were first described in 1970 with glioblastoma cells (9). These three-dimensional (3D) spheroids are considered to superiorly replicate the tumor environment, since spheroids allow cell-cell and cell-matrix contacts. As for the effectiveness of chemotherapeutic agents, the gradient of drug concentration in tumors plays an important role (10). Furthermore, the expression of surviving factors figures prominently in drug resistance (11). Studies have shown divergent response rates in colorectal carcinoma cells due to different protein expression profiles (11).

The extracellular matrix appears to be one significant factor for the resistance of a variety of cancer cells to radiation (12). Another significant factor for radioresistance is hypoxia in tumor cells. A lack of oxygen is often discussed as a mechanism for consecutive radioresistance and has been reported in human glioma cell lines (13).

In HNSCC, one important issue is the susceptibility of a patient to radiotherapy, since $20 \%$ of patients only achieve 
a partial response or no response to irradiation (14). Another key problem is recurrence (15), since up to $50 \%$ of the patients are confronted with recurrent disease (16). The spheroid cell model may explain tumor biology more precisely and actualize therapy outcomes already in in vitro models. However, only limited data for 3D HNSCC cell models in comparison to 2D cell culture models is available (17-19).

Therefore, the present study sought to establish stable HNSCC spheroid protocols and accentuate its different features compared with $2 \mathrm{D}$ cell culture methods. Thus, the present study assessed the expression of important HNSCC proteins in the spheroids and compared the results with a $2 \mathrm{D}$ cell model. Ultimately, an established cytotoxicity protocol was established, and radiation and chemotherapy treatments were compared in each model.

\section{Materials and methods}

Cell Culture. The HNSCC SCC25, CAL27 and FaDu cell lines were obtained from the American Type Culture Collection (Manassas, VA, USA) or the German Collection of Microorganisms and Cell Cultures (Braunschweig, Germany). The tumor cells were cultured as described previously (20). In brief, monolayer cells were grown in RPMI medium supplemented with $1 \%$ penicillin-streptomycin and $10 \%$ fetal bovine serum (all Gibco BRL, Gaithersburg, MD, USA). Spheroids were grown in Dulbecco's modified Eagle's medium Ham's F-12 (Lonza, Verviers, Belgium) enriched with epidermal growth factor (EGF; Sigma-Aldrich, St. Louis, MO, USA), basic fibroblast growth factor (bFGF; Sigma-Aldrich) and B27 (Invitrogen Life Technologies, Carlsbad, CA, USA) supplement to conduce multicellular growth; these are commonly used supplements in free-floating spheroid models. The two cell models were cultured in a humidified $5 \% \mathrm{CO}_{2}$ atmosphere at $37^{\circ} \mathrm{C}$.

Cytotoxicity assay. For the assessment of growth inhibition, cell counting kit 8 (CCK-8; Dojindo Molecular Technologies Inc., Gaithersburg, MD, USA) was used. For the 2D cell culture, the assay was performed according to the manufacturer's instructions. Hence, $3 \times 10^{3}$ cells per well were added to 96 -well plates (Sarstedt, Inc., Newton, NC, USA) and allowed to rest for $24 \mathrm{~h}$. For the 3D cell culture, $2 \times 10^{4}$ cells per well were seeded into Ultra Low Attachment plates (Costar, Corning Life Sciences, Tewksbury, MA, USA) and allowed to rest for $72 \mathrm{~h}$. In each culture model, the cells were treated with increasing concentrations of cisplatin $(0-20 \mu \mathrm{M})$ or radiation doses $(0,2,4,6$ and $8 \mathrm{~Gy}$ ) using a conventional radiation source with $150-\mathrm{kV}$ X-rays (dose rate, $1 \mathrm{~Gy} / 0.73 \mathrm{~min}$ ). After $72 \mathrm{~h}$ of incubation, cell growth was measured. All experiments were carried out in triplicate and performed as at least three independent experiments.

Immunohistochemistry. In the $2 \mathrm{D}$ cell model, $7.5 \times 10^{4}$ cells were spun onto microscopic slides using a Shandon Cytospin II centrifuge (130 x g for $3 \mathrm{~min}$; Thermo Fisher Scientific, Waltham, MA, USA) fixated with acetone for $3 \mathrm{~min}$ at $4^{\circ} \mathrm{C}$. For the $3 \mathrm{D}$ cell model, spheroids were grown as aforementioned. After 5 days, the spheroids were fixated in $8 \%$ formaldehyde solution for $30 \mathrm{~min}$, and consecutively casted with $4 \%$ agarose gel and stored in phosphate-buffered saline at $7^{\circ} \mathrm{C}$ until paraffinization. Ultimately, tumor sections of a 2-3- $\mu$ m thickness were created.
Immunohistochemical staining was performed as previously described $(20,21)$. The three cell lines were stained for Ki-67, vascular endothelial growth factor receptor (VEGFR), EGF receptor (EGFR) and survivin. Ki-67 serves as a proliferation marker (22), VEGFR is an (lymph) angiogenesis receptor (23), EGFR is a member of the Her/ erbB receptor family and an important receptor tyrosine kinase in HNSCC (24), and survivin is described as an apoptotic inhibitory protein (25). Primary antibodies for Ki-67 (monoclonal rabbit antibody; Abcam, Cambridge, MA, USA; dilution, 1:400), VEGFR (polyclonal rabbit antibody; Sigma-Aldrich; dilution, 1:100), EGFR (monoclonal rabbit antibody; Abcam; dilution, 1:100) and survivin (monoclonal rabbit antibody; Abcam; dilution, 1:500) were applied for $60 \mathrm{~min}$. A polymer enhancer was used for $10 \mathrm{~min}$ prior to adding the high-resolution polymer (Thermo Fisher Scientific) for $15 \mathrm{~min}$. Slides were developed using diaminobenzidine reagent (Thermo Fisher Scientific), counterstained with hematoxylin, dehydrated and mounted under a coverslip. Samples were analyzed using an Olympus BH-2 microscope (Olympus Corporation, Tokyo, Japan) and assigned to one of four categories of marker expression: $0,<5 \%$; 1 (weak), $5-30 \%$; 2 (moderate), 30-60\%; and 3 (strong), 60-100\%. An average expression score was calculated for every cell line. Experiments were repeated three times and histological analysis was performed by two independent investigators.

Statistical analysis. Data was analyzed by Student's t-test or one-way analysis of variance using SPSS software version 21 (IBM SPSS, Armonk, NY, USA). P<0.05 was considered to indicate a statistically significant difference. All experiments were repeated at least three times. Error bars represent the standard error of the mean.

\section{Results}

Spheroid cell growth. Culturing of the HNSCC SCC25, CAL27 and $\mathrm{FaDu}$ cell lines according to the 3D protocol showed that all three cell lines exhibit certain degrees of spheroid growth. The FaDu cells showed the best cluster shape, cell-cell adherence and spheroid size (Fig. 1A). The SCC25 cells grew in denser and rounded clusters, whereas the CAL27 cells formed long and loose clusters (Fig. 1B and C).

Inhibitory concentrations of cisplatin. To establish a 3D cytotoxicity assay, different cell counts were seeded. After various incubation times ( $48 \mathrm{~h}$ for FaDu cells; $72 \mathrm{~h}$ for CAL27 and SCC25 cells), the cells were submitted to cisplatin treatment. The metabolic activity in the FaDu cell line was strongest as it led to an intense change of color in the CCK- 8 assay. While the SCC25 cells showed less enzymatic conversion, the 3D culture of the CAL27 cells did not lead to feasible results in this assay. Hence, growth inhibition experiments were continued with $\mathrm{FaDu}$ and SCC25 cell lines.

In the 2D cell model, the cells were incubated with cisplatin concentrations ranging from $0-20 \mu \mathrm{M}$. In the two cell lines, cisplatin led to strong growth inhibition, with a half maximal inhibitory concentration $\left(\mathrm{IC}_{50}\right)$ of $0.95 \mu \mathrm{M}$ in the FaDu cells and $3.26 \mu \mathrm{M}$ in the SCC25 cells. By contrast, the spheroids were less susceptible to cisplatin, with an $\mathrm{IC}_{50}$ of 
Table I. Immunohistochemical analysis results showing average protein expression levels for Ki-67, VEGFR, EGFR and survivin in 2D and 3D cell models.

\begin{tabular}{|c|c|c|c|c|c|}
\hline Parameter & SCC25 & CAL27 & $\mathrm{FaDu}$ & $2 \mathrm{D}: 3 \mathrm{D}$ & P-value \\
\hline \multicolumn{6}{|l|}{ Ki-67 } \\
\hline $2 \mathrm{D}$ & 2.7 & 2.5 & 2.3 & \multirow{2}{*}{3.2} & \multirow{2}{*}{0.0134} \\
\hline $3 \mathrm{D}$ & 0.7 & 0.7 & 1.0 & & \\
\hline \multicolumn{6}{|l|}{ VEGFR } \\
\hline $2 \mathrm{D}$ & 2.5 & 2.8 & 2.0 & \multirow[t]{2}{*}{1.2} & \multirow[t]{2}{*}{0.7289} \\
\hline $3 \mathrm{D}$ & 3.0 & 1.5 & 1.5 & & \\
\hline \multicolumn{6}{|l|}{ EGFR } \\
\hline $2 \mathrm{D}$ & 2.8 & 1.0 & 2.3 & \multirow[t]{2}{*}{0.7} & \multirow[t]{2}{*}{0.4460} \\
\hline $3 \mathrm{D}$ & 3.0 & 3.0 & 2.8 & & \\
\hline \multicolumn{6}{|l|}{ Survivin } \\
\hline $2 \mathrm{D}$ & 2.8 & 2.8 & 3.0 & \multirow[t]{2}{*}{1.1} & \multirow[t]{2}{*}{0.0595} \\
\hline $3 \mathrm{D}$ & 2.6 & 2.6 & 3.0 & & \\
\hline
\end{tabular}

Samples were categorized to one of four expression levels: 0,<5\%; 1 (weak), 5-30\%; 2 (moderate), 30-60\%; and 3 (strong), 60-100\%, and then an average expression score was calculated. VEGFR, vascular endothelial growth factor receptor; EGFR, epidermal growth factor receptor; 2D, two-dimensional; 3D, three-dimensional.

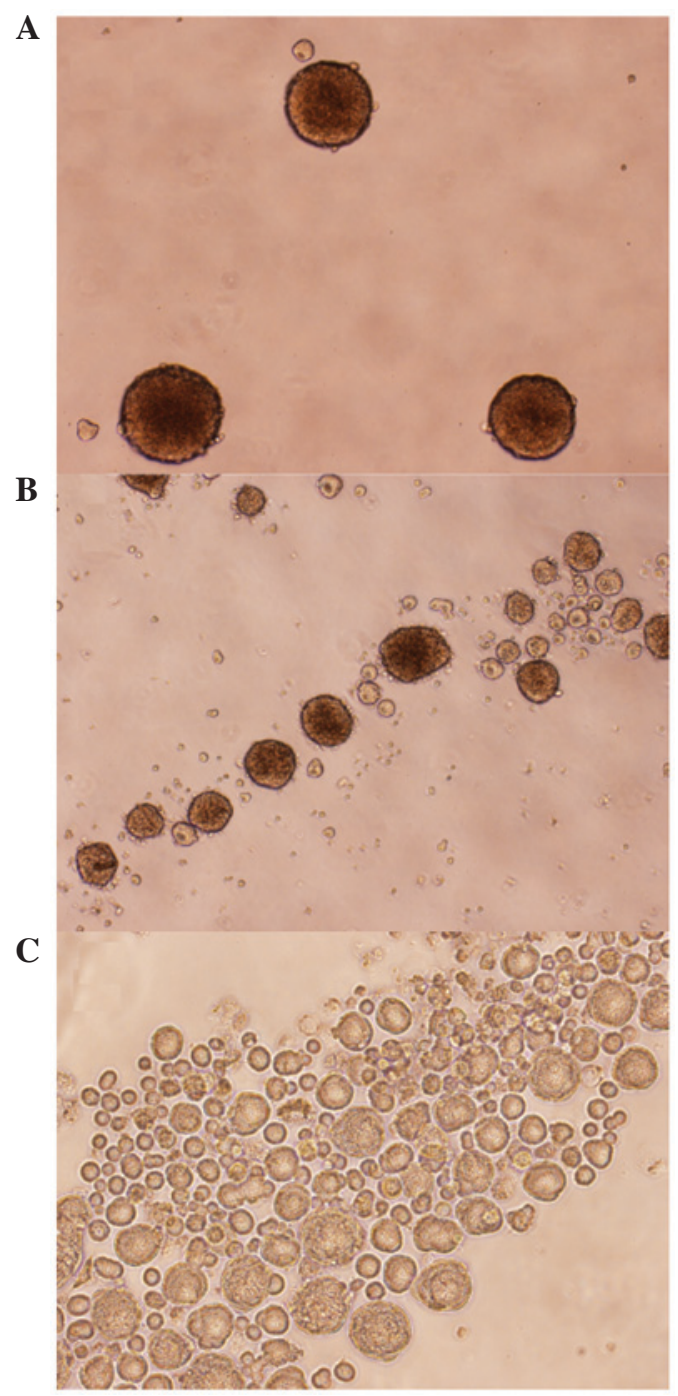

Figure 1.Microscopicimages of 5-day-old spheroids of headandnecksquamous cell carcinoma (A) FaDu, (B) CAL27 and (C) SCC25 cells (magnification, x40).
$2.31 \mu \mathrm{M}$ in the FaDu cells and $150.30 \mu \mathrm{M}$ in the SCC25 cells. Dose-response curves for each cell line and culture model are shown in Fig. 2.

Response to radiation. The cells were exposed to increasing doses of radiation (0-8 Gy). Dose-response curves are depicted in Fig. 3. In the FaDu cell line, a comparable response to irradiation was observed in each cell model. However, in the SCC25 cells, the $2 \mathrm{D}$ cell model was significantly more susceptible to irradiation, since the spheroids showed no growth inhibition even after 8 Gy in the 3D model.

Immunohistochemical staining. The cell culture models were compared with regard to the expression of Ki-67, VEGFR, EGFR and survivin. Average expression scores were calculated and a 2D:3D ratio was established. Expression levels and ratios for all cell lines and proteins are summarized in Table I. With regard to $\mathrm{Ki}-67$, moderate to strong staining was detected in the 2D model in all three cell lines, and the average staining score was three times higher than in the $3 \mathrm{D}$ cell model $(\mathrm{P}=0.0134)$. Staining was observed in a high percentage of cells. By contrast, only a few cells were stained with Ki-67 in the 3D model. The majority of the Ki-67-expressing cells were located in the outer third of a spheroid, solitary cells were observed in the intermediary zone and no Ki-67 staining was observed in the necrotic center (Fig. 4A and B).

The expression of VEGFR in the monolayer culture was likewise ubiquitous, although FaDu showed less staining. In the spheroids, VEGFR was expressed through all layers of the cell cluster. In the CAL27 cells, lesser staining was observed in the 3D cell model compared with the 2D model, whereas in the SCC25 and FaDu cells an inverse staining pattern was assessed (Fig. 4C and D). In the CAL27 cells, only weak staining of EGFR was observed in the monolayer model. However, in the 3D culture, the CAL27 cells strongly 

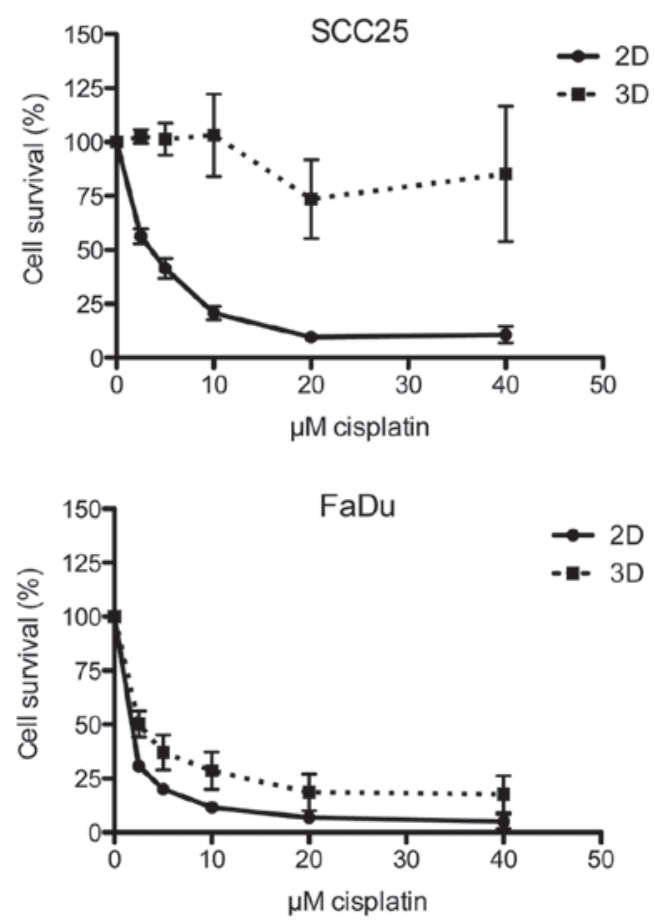

Figure 2. Dose-response curves of head and neck squamous cell carcinoma SCC25 and FaDu cell lines in the presence of increasing doses of cisplatin after $72 \mathrm{~h}$ of incubation. All experiments were performed in triplicate and repeated three times, and the data are presented as the mean and standard error of the mean. 2D, two-dimensional; 3D, three-dimensional.
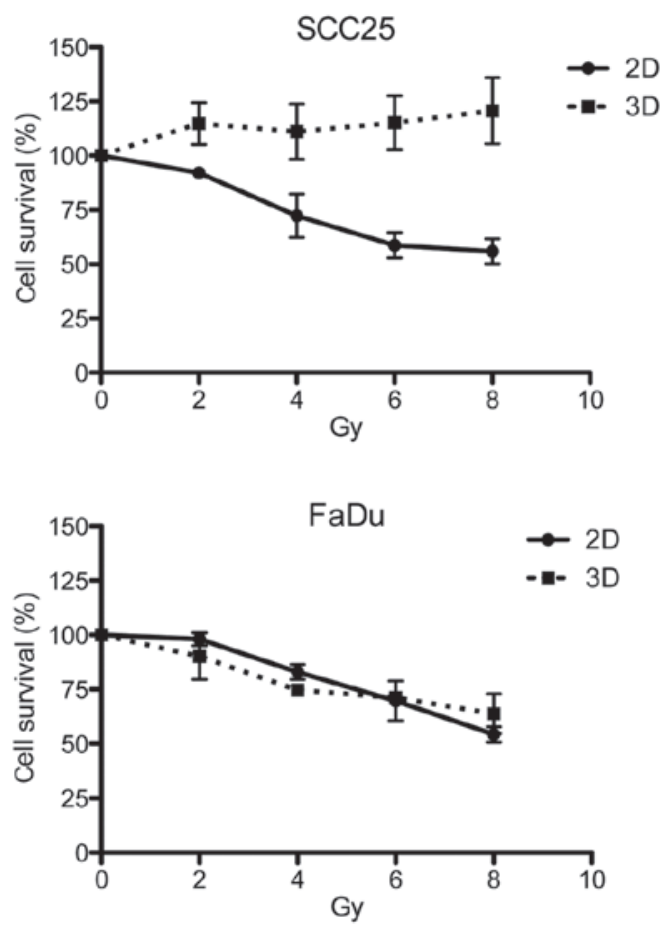

Figure 3. Surviving cell fraction after sole radiotherapy in the head and neck squamous cell carcinoma SCC25 and FaDu cell lines. The cells were treated with increasing doses of radiation ranging from 2-8 Gy. 2D, two-dimensional; 3D, three-dimensional.

expressed EGFR. In the FaDu and SCC25 cells, moderate to high expression was observed compared with high expression in the spheroids (Fig. 4E and F).
A

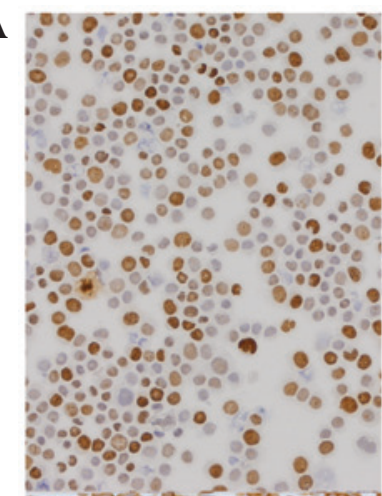

B

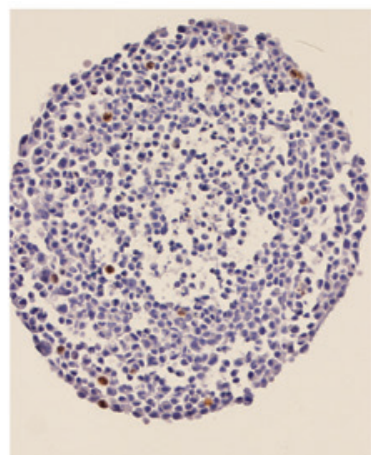

C

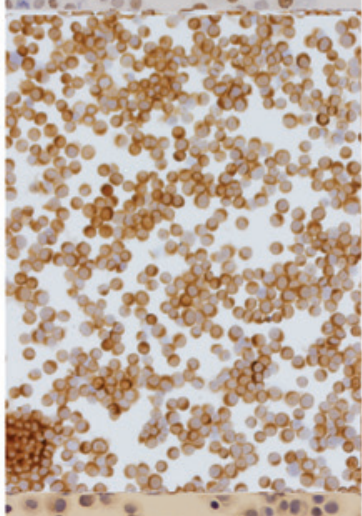

D

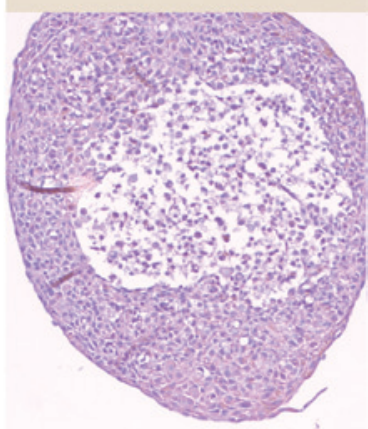

E

$\mathbf{F}$

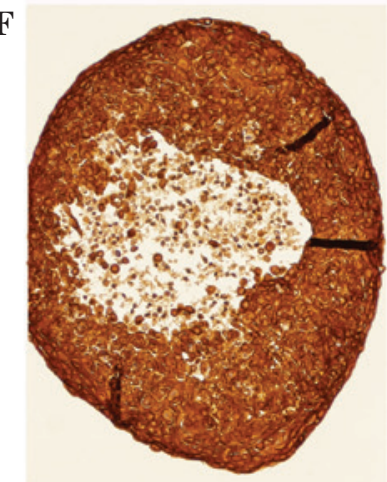

G

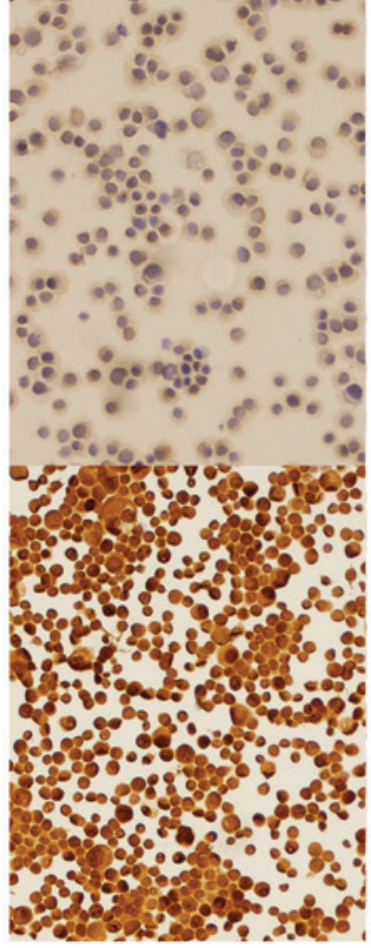

$\mathbf{H}$

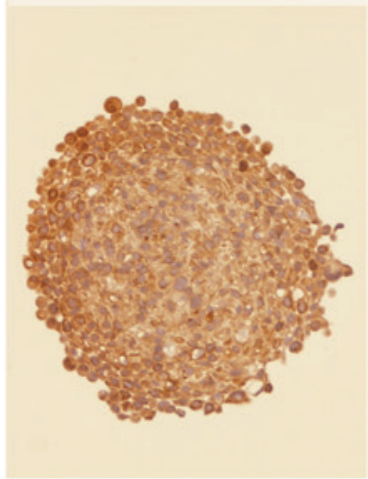

Figure 4. Immunohistochemical staining of head and neck squamous cell carcinoma spheroids 5 days after dissemination. (A) FaDu cells were spun onto slides, fixated and stained with Ki-67 in the monolayer model. (B) Staining of a spheroid (diameter, $300 \mu \mathrm{m}$ ) of FaDu cells with Ki-67 antibody for the 3D model. Vascular endothelial growth factor staining of the CAL27 cells in (C) monolayer and (D) spheroid cell cultures. Epithelial growth factor staining in the CAL27 cells in the (E) 2D and (F) spheroid cell models. Survivin expression of the SCC25 cells in the $(\mathrm{G}) 2 \mathrm{D}$ and $(\mathrm{H})$ spheroid cell models. All images were captured at x100 magnification.

With regard to survivin, no differential expression was observed in the $2 \mathrm{D}$ cell model compared with the $3 \mathrm{D}$ cell model (Fig. 4G and H). 


\section{Discussion}

The capability of spheroid cell culture to reflect cancer biology more accurately in vitro has been described in various studies $(4,11,26,27)$. Attempted explanations for the proximity of spheroid models to in vivo tumors in terms of proliferation and therapy response include cell heterogeneity and tumor microenvironment (28) or different levels of drug and oxygen diffusion (26).

To date, a certain number of studies on HNSCC spheroids have been published (29-46) but there is little knowledge on contraposing 2D to 3D cell cultures. These previous studies have focused on novel drug treatments or molecular expression patterns in $3 \mathrm{D}$ cell models. Therefore, although there is a broad knowledge regarding 3D cell cultures in HNSCC, a direct comparison between 2D and 3D cell cultures in HNSCC remains to be investigated. Hence, the present study aimed to establish a stable protocol for an HNSCC spheroid cell culture and to compare important attributes between the conventional monolayer and this spheroid cell culture. As expected from the previously mentioned studies, all three HNSCC cell lines, SCC25, CAL27 and FaDu, were able to grow in multicellular spheroids. Their growth patterns, however, differed between the cell lines and CAL27 did not exhibit reliable stability. Hence, this cell line was excluded from the cytotoxicity assays.

The capability of spheroid cell culture to better reflect cancer therapy resistance cultures has previously been described in hepatocellular (5) and colon (47) carcinoma. Since cisplatin is the main chemotherapeutic drug in the treatment of HNSCC, the present study exposed spheroids to cisplatin and compared the results to a monolayer cell culture. For the first time, a significant increase was observed in the $\mathrm{IC}_{50}$ dose in one cell line, while comparable results were shown by each of the culture models in the other cell line. The site of origin may serve as an explanation, since SCC25 is derived from a tongue cancer and $\mathrm{FaDu}$ is from a hypopharyngeal tumor.

Since radiotherapy is a vital factor in HNSCC therapy and radioresistance is a determinative problem, the spheroids were irradiated. Notably, diverging growth inhibition was observed in the cell lines. In the FaDu cells, surviving fractions comparable to the monolayer cell culture were found, whereas in the SCC25 cells, the spheroids were significantly less affected by radiation than the monolayers.

Observations of resistance to irradiation have also been described in glioma cells (48). In the present study, an intermediate layer of hypoxia surrounding the center of spheroids was described; therefore, irradiation had less effect on spheroids. In addition, the protein expression of Ki-67 was examined within the spheroids. As expected, staining was concentrated at the periphery, since $\mathrm{Ki}-67$ is considered as a proliferation marker (22). VEGFR was expressed throughout the whole spheroid. This finding is in contrast to that of a study by Shweiki et al, which described the weaker expression of VEGFR in the periphery of glial rat tumor spheroids (49).

However, comparing the location of primary expression in spheroids and the monolayer model is not possible, since 2D cells are prepared prior to the staining process. However, the staining intensity can be assessed and compared. In the present study, a variation in staining intensity was noted for Ki-67, VEGFR and EGFR, with partly stronger and partly weaker expression in the spheroid cell model. Since VEGFR expression may result from hypoxia and cellular stress (50), lower expression was expected in the monolayer culture. However, only one cell line (CAL27) exhibited this pattern. Likewise, a similar expression pattern of EGFR was observed in the SCC25 and FaDu cells, whereas the CAL27 cells showed stronger expression in the spheroids. As for survivin, different staining intensities were expected, as described in a previous study (51). However, no distinction was possible between the spheroids and monolayer cells.

A spheroid cell culture was established from the HNSCC cell lines in the present study. The study described their response to cisplatin and radiotherapy for the first time. Despite being of the same cell line, different protein expression intensities and/or staining patterns were observed between spheroids and monolayer cell cultures. Hence, growth in spheroids alone alters the cellular pathways in the HNSCC cell lines. Thus, spheroid cell culture may prove to be the more rational alternative for cell culture due to the more physiological growth of the cells. Limiting factors, however, are higher costs, more elaborate maintenance and the impracticality of certain cell lines.

\section{References}

1. Jemal A, Bray F, Center MM, Ferlay J, Ward E and Forman D: Global cancer statistics. CA Cancer J Clin 61: 69-90, 2011.

2. Myers EN. Head and neck oncology - 2010, part II. Otolaryngol Pol 64: 204-214, 2010.

3. Carvalho AL, Nishimoto IN, Califano JA and Kowalski LP: Trends in incidence and prognosis for head and neck cancer in the United States: A site-specific analysis of the SEER database. Int J Cancer 114:806-816, 2005.

4. Kimlin LC, Casagrande $\mathrm{G}$ and Virador VM: In vitro three-dimensional (3D) models in cancer research: An update. Mol Carcinog 52: 167-182, 2013.

5. Bokhari M, Carnachan RJ, Cameron NR and Przyborski SA: Culture of HepG2 liver cells on three dimensional polystyrene scaffolds enhances cell structure and function during toxicological challenge. J Anat 211:567-576, 2007.

6. Shain KH and Dalton WS: Cell adhesion is a key determinant in de novo multidrug resistance (MDR): New targets for the prevention of acquired MDR. Mol Cancer Ther 1: 69-78, 2001.

7. Johnson JI, Decker S, Zaharevitz D, Rubinstein LV, Venditti JM, Schepartz S, et al: Relationships between drug activity in NCI preclinical in vitro and in vivo models and early clinical trials. $\mathrm{Br}$ J Cancer 84: 1424-1431, 2001.

8. Voskoglou-Nomikos T, Pater JL and Seymour L: Clinical predictive value of the in vitro cell line, human xenograft, and mouse allograft preclinical cancer models. Clin Cancer Res 9: 4227-4239, 2003.

9. Sutherland RM, McCredie JA and Inch WR: Growth of multicell spheroids in tissue culture as a model of nodular carcinomas. J Natl Cancer Inst 46: 113-120, 1971.

10. Horning JL, Sahoo SK, Vijayaraghavalu S, Dimitrijevic S, Vasir JK, Jain TK, et al: 3-D tumor model for in vitro evaluation of anticancer drugs. Mol Pharm 5: 849-862, 2008.

11. Karlsson H, Fryknäs M, Larsson R and Nygren P: Loss of cancer drug activity in colon cancer HCT-116 cells during spheroid formation in a new 3-D spheroid cell culture system. Exp Cell Res 318: 1577-1585, 2012.

12. Cordes $\mathrm{N}$ and Meineke V: Cell adhesion-mediated radioresistance (CAM-RR). Extracellular matrix-dependent improvement of cell survival in human tumor and normal cells in vitro. Strahlenther Onkol 179: 337-344, 2003.

13. Khaitan D, Chandna S, Arya MB and Dwarakanath BS: Establishment and characterization of multicellular spheroids from a human glioma cell line; Implications for tumor therapy. J Transl Med 4: 12, 2006.

14. Lim Y,Keam B, Koh Y,Kim TM,Lee S-H, Hah JH, et al: Clinical outcomes of radiation-based locoregional therapy in locally advanced head and neck squamous cell carcinoma patients not responding to induction chemotherapy. Oral Surg Oral Med Oral Pathol Oral Radiol 116: 55-60, 2013 
15. Vermorken JB and Specenier P: Optimal treatment for recurrent/metastatic head and neck cancer. Ann Oncol 21 (Suppl 7): vii252-vii261, 2010.

16. Ho AS, Tsao GJ, Chen FW, Shen T, Kaplan MJ, Colevas AD, et al: Impact of positron emission tomography/computed tomography surveillance at 12 and 24 months for detecting head and neck cancer recurrence. Cancer 119: 1349-1356, 2013.

17. Eke I, Schneider L, Förster C, Zips D, Kunz-Schughart LA and Cordes N: EGFR/JIP-4/JNK2 signaling attenuates cetuximab-mediated radiosensitization of squamous cell carcinoma cells. Cancer Res 73: 297-306, 2013.

18. Colley HE, Hearnden V, Avila-Olias M, Cecchin D, Canton I, Madsen J, et al: Polymersome-mediated delivery of combination anticancer therapy to head and neck cancer cells: $2 \mathrm{D}$ and $3 \mathrm{D}$ in vitro evaluation. Mol Pharm 11: 1176-1188, 2014.

19. Eke I, Leonhardt F, Storch K, Hehlgans S and Cordes N: The small molecule inhibitor QLT0267 Radiosensitizes squamous cell carcinoma cells of the head and neck. PLoS One 4: e6434, 2009.

20. Kotowski U, Heiduschka G, Brunner M, Czembirek C, Eder-Czembirek C, Schmidt R, et al: Radiosensitization of head and neck cancer cells by the phytochemical agent sulforaphane. Strahlenther Onkol 187: 575-580, 2011.

21. Lill C, Schneider S, Pammer J, Loewe R, Gedlicka W, Houben R, et al: Significant correlation of peptidyl-prolyl isomerase overexpression in Merkel cell carcinoma with overall survival of patients. Head Neck 33: 1294-1300, 2011.

22. Xu W: CD133 and Ki-67 expression is associated with gastrointestinal stromal tumor prognosis. Oncol Lett 6: 1289-1294, 2013

23. Gildener-Leapman N, Ferris RL and Bauman JE: Promising systemic immunotherapies in head and neck squamous cell carcinoma. Oral Oncol 49: 1089-1096, 2013.

24. Erjala K, Sundvall M, Junttila TT, Zhang N, Savisalo M, Mali P, et al: Signaling via ErbB2 and ErbB3 associates with resistance and epidermal growth factor receptor (EGFR) amplification with sensitivity to EGFR inhibitor gefitinib in head and neck squamous cell carcinoma cells. Clin Cancer Res 12: 4103-4111, 2006.

25. Ye Q, Cai W, Zheng Y, Evers BM and She QB: ERK and AKT signaling cooperate to translationally regulate survivin expression for metastatic progression of colorectal cancer. Oncogene 33: 1828-1839, 2014.

26. Desoize B, Gimonet D and Jardiller JC: Cell culture as spheroids: An approach to multicellular resistance. Anticancer Res 18 4147-4158, 1998

27. Elliott NT and Yuan F: A review of three-dimensional in vitro tissue models for drug discovery and transport studies. J Pharm Sci 100: 59-74, 2011.

28. Lee GY, Kenny PA, Lee EH and Bissell MJ: Three-dimensional culture models of normal and malignant breast epithelial cells. Nat Methods 4: 359-365, 2007.

29. Ingargiola M, Runge R, Heldt J-M, Freudenberg R, Steinbach J, Cordes N, et al: Potential of a Cetuximab-based radioimmunotherapy combined with external irradiation manifests in a 3-D cell assay. Int J Cancer 135: 968-980, 2014

30. Rasanen K, Sriswasdi S, Valiga A, Tang H-Y, Zhang G, Perego M, et al: Comparative secretome analysis of epithelial and mesenchymal subpopulations of head and neck squamous cell carcinoma identifies S100A4 as a potential therapeutic target. Mol Cell Proteomics 12: 3778-3792, 2013.

31. Yan M, Yang X, Wang L, Clark D, Zuo H, Ye D, et al: Plasma membrane proteomics of tumor spheres identify CD166 as a novel marker for cancer stem-like cells in head and neck squamous cell carcinoma. Mol Cell Proteomics 12: 3271-3284, 2013.

32. Waldron NN, Barsky SH, Dougherty PR and Vallera DA: A bispecific EpCAM/CD133-targeted toxin is effective against carcinoma. Target Oncol 9: 239-249, 2014.

33. Yang W-H, Lan H-Y, Tai S-K and Yang M-H: Repression of bone morphogenetic protein 4 by let-7i attenuates mesenchymal migration of head and neck cancer cells. Biochem Biophys Res Commun 433: 24-30, 2013.
34. Chang CC, Hsu WH, Wang CC, Chou CH, Kuo MYP, Lin BR, et al: Connective tissue growth factor activates pluripotency genes and mesenchymal-epithelial transition in head and neck cancer cells. Cancer Res 73: 4147-4157, 2013.

35. Dennis M, Wang G, Luo J, Lin Y, Dohadwala M, Abemayor E, et al: Snail controls the mesenchymal phenotype and drives erlotinib resistance in oral epithelial and head and neck squamous cell carcinoma cells. Otolaryngol Head Neck Surg 147: 726-732, 2012.

36. Duarte S, Loubat A, Momier D, Topi M, Faneca H, Pedroso de Lima MC, et al: Isolation of head and neck squamous carcinoma cancer stem-like cells in a syngeneic mouse model and analysis of hypoxia effect. Oncol Rep 28: 1057-1062, 2012.

37. Chen Y-S, Wu M-J, Huang C-Y, Lin S-C, Chuang T-H, Yu C-C and Lo JF: CD133/Src axis mediates tumor initiating property and epithelial-mesenchymal transition of head and neck cancer. PLoS One 6: e28053, 2011.

38. Lim YC, Oh S-Y, Cha YY, Kim S-H, Jin X, Kim H. Cancer stem cell traits in squamospheres derived from primary head and neck squamous cell carcinomas. Oral Oncol 47: 83-91, 2011.

39. Krishnamurthy S, Dong Z, Vodopyanov D, Imai A, Helman JI, Prince ME, et al: Endothelial cell-initiated signaling promotes the survival and self-renewal of cancer stem cells. Cancer Res 70: 9969-9978, 2010.

40. Kross KW, Heimdal JH, Olsnes C, Olofsson J and Aarstad HJ: Co-culture of head and neck squamous cell carcinoma spheroids with autologous monocytes predicts prognosis. Scand J Immunol 67: 392-399, 2008.

41. Harper LJ, Piper K, Common J, Fortune F and Mackenzie IC Stem cell patterns in cell lines derived from head and neck squamous cell carcinoma. J Oral Pathol Med 36: 594-603, 2007.

42. Olsnes C, Heimdal J-H, Kross KW, Olofsson J and Aarstad HJ: Viable head and neck tumor spheroids stimulate in vitro autologous monocyte MCP-1 secretion through soluble substances and CD14/lectin-like receptors. Eur Arch Otorhinolaryngol 262: 953-960, 2005 .

43. Kross KW, Heimdal J-H, Olsnes C, Olofsson J and Aarstad HJ: Head and neck squamous cell carcinoma spheroid- and monocyte spheroid-stimulated IL-6 and monocyte chemotactic protein-1 secretion are related to TNM stage, inflammatory state and tumor macrophage density. Acta Otolaryngol 125: 1097-1104, 2005

44. Heimdal JH, Olsnes C, Olofsson J and Aarstad HJ: Monocyte and monocyte-derived macrophage secretion of MCP-1 in co-culture with autologous malignant and benign control fragment spheroids. Cancer Immunol Immunother 50: 300-306, 2001

45. Heimdal JH, Aarstad HJ, Olsnes C and Olofsson J: Human autologous monocytes and monocyte-derived macrophages in co-culture with carcinoma F-spheroids secrete IL-6 by a non-CD14-dependent pathway. Scand J Immunol 53: 162-170, 2001.

46. Heimdal J, Aarstad HJ and Olofsson J: Monocytes secrete interleukin-6 when co-cultured in vitro with benign or malignant autologous fragment spheroids from squamous cell carcinoma patients. Scand J Immunol 51: 271-278, 2000

47. Fayad W, Brnjic S, Berglind D, Blixt S, Shoshan MC Berndtsson M, et al: Restriction of cisplatin induction of acute apoptosis to a subpopulation of cells in a three-dimensional carcinoma culture model. Int J Cancer 125: 2450-2455, 2009.

48. Sminia P, Acker H, Eikesdal HP, Kaaijk P, Enger PØ, Slotman B and Bjerkvig R: Oxygenation and response to irradiation of organotypic multicellular spheroids of human glioma. Anticancer Res 23: 1461-1466, 2003.

49. Shweiki D, Neeman M, Itin A and Keshet E: Induction of vascular endothelial growth factor expression by hypoxia and by glucose deficiency in multicell spheroids: Implications for tumor angiogenesis. Proc Natl Acad Sci USA 92: 768-772, 1995.

50. Sivaraj KK, Takefuji M, Schmidt I, Adams RH, Offermanns S and Wettschureck N: G13 controls angiogenesis through regulation of VEGFR-2 expression. Dev Cell 25: 427-434, 2013.

51. Töyli M, Rosberg-Kulha L, Capra J, Vuoristo J and Eskelinen S: Different responses in transformation of MDCK cells in 2D and 3D culture by v-Src as revealed by microarray techniques, RT-PCR and functional assays. Lab Invest 90: 915-928, 2010. 